\title{
Recent patents in stem cell research
}

\begin{abstract}
Patent \#
Subject

WO 9858963

Preparation of large amounts of human monoclonal antibodies by transplanting a human stem cell into a first and second animal embryo, and injecting the first embryo with antigen and the second embryo with cells from first embryo.

US 5851832 Culture of mammalian neural cells enriched with multipotent neural stem cells in vitro, for the production of differentiated neural cells.

US 5849553 Transforming neural crest stem cells with a vector containing an immortalized gene flanked by recombinase target sites, for the production of an immortalized cell line. Cells can be used for transplantation, for the production of monoclonal antibodies, and to grow smooth muscle cells.

WO 9854225 Monoclonal antibodies compatible with humans, specific for human CD28 and capable of nonantigen specifically activating T-lymphocytes; used in the treatment of diseases with a pathologically low CD4 T-cell number, especially AIDS or after stem cell transplantation or chemotherapy.
\end{abstract}

WO 9851781 Transgenic mice expressing nonnative presenilin-1 mutant or allele, and associated methods to target mouse embryonic stem cells, to provide a model system to study the etiology of familial Alzheimer's disease.

US 5837507 Stem cell transduced to express HOX gene able to form pluripotent cells, especially for producing expanded cel populations for bone marrow reconstitution without the risk of leukemia, or as carriers for therapeutic genes.

WO 9848001 Production of neurons or smooth muscle cells, by contacting at least one mammalian neural stem cell with a growth factor, especially transforming growth factor.

WO 9846726 Transgenic nonhuman animal or stem cell with a disrupted A-myb locus in the genome; useful as a model for male infertility and for studying spermatogenesis.

WO 9846733 Preparation of transgenomic embryonic stem cell with a whole heterologous chromosome to produce a transgenic organism; com- Technol. \& Med. prises tagging the chromosome with a dominant marker, inducing (London) microcell formation, and fusing microcells with embryonic cells.

WO 9845326 Polynucleotides encoding stem cell zinc fingers; useful for gene therapy to replace or supplement defective gene for those proteins.

WO 9842838 Production of cells expressing a heterologous histocompatibility allele by deleting regions of the histocompatibility gene complex and replacing them with a polynucleotide encoding a heterologous allele; useful for preparing cells having a preselected expression of $\mathrm{MHC}$ antigens.

WO 9842356 In vitro elimination of tumor cells from hematopoietic cells (specifically enriched in stem cells) by labeling, recording an image, and directing a laser beam to individual labeled cells, particularly bone marrow cells; treated cells can be reintroduced into a patient, e.g., in the treatment of cancer.

EP 867720 Counting hematopoietic progenitor cells using flow cytometry without the use of antibodies; used to monitor the mobilization of stem cells for use in peripheral blood stem cell transplantation (e.g., for treating chemotherapy and/or radiotherapy patients).

WO 9840468 Production of selected cell lines or transgenic animals by introducing a vector with a selectable marker into an embryonic stem cell gene, so that expression of the gene is inhibited.

Assignee

Wengler GS

Canada)

Cal. Inst. Technol.

(Pasadena, CA)

Huenig T

Merck \& Co.

Humphries K;

Sauvageau G;

Univ. California

(Oakland, CA)

Cal. Inst. Technol.

(Pasadena, CA)

Temple Univ.

(Philadelphia, PA)

Osiris Therapeutics

(Alachua, FL)

Palsson, BO
Toa Medical

Electronics Co

(Japan)

Vanderbilt Univ. (Nashville, TN)

Author

Date

Status

Wengler GS

$12 / 30 / 98$

A1

Neurospheres Ltd. Baetge EE,

(Calgary, Alberta, Hammang JP,

Reynolds B, Weiss S

Anderson DJ,

$12 / 15 / 98$

Stemple DL

$12 / 22 / 98$

A

Hanke G, Hanke T,

$12 / 3 / 98$

A2

Huenig T, Rodriguez-

Palermo M, Tacke M,

Hara $T$

Jiang P, Qian S,

$11 / 19 / 98$

A1

Whitehouse Sta., Sisodia SS, van der

NJ); Johns Hopkins Ploeg LHT, Wong PC,

Univ. (Baltimore, MD) Zheng $\mathrm{H}$

Humphries K,

$11 / 17 / 98$

A

Largman C

Lawrence HJ,

Sauvageau G

Anderson DJ,

$10 / 29 / 98$

A1

Shah NM

Hatton K, Reddy EP, 10/22/98

A1

Toscani A

Fisher E, Hernandez

$10 / 22 / 98$

A1

$\mathrm{D}$, Martin J, Mee J,

Tybulewicz V

Civin Cl, Liu C

$10 / 15 / 98$

A1

Morphogenesis Inc. Lawman MJP,

$10 / 1 / 98$

Lawman P

Palsson, BO

10/1/98

A1

Hamaguchi Y,

$9 / 30 / 98$

A1

Houwen B, Ikeuchi $Y$,

Morikawa T, Tsujino Y

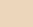

政

